\title{
Norduz ve Kıl Keçilerin Teke Katımı Dönemi Bazı Üreme Özellikleri
}

\section{Kadir KIRK ${ }^{* 1}[\mathbb{C}$}

\author{
${ }^{1}$ Yüzüncü Yıl Üniversitesi Ziraat Fakültesi Zootekni Bölümü, 65080, Kampüs/Tuşba-Van
}

Öz: Bu araştırma, Van ili Muradiye ilçesi, ekstansif koşullarda toplam 486 baş'ık küçükbaş hayvan sürüsünde 2,3,4,5 ve 6> yaş gruplarında 48 baş Norduz 69 baş Kıl keçi, 4 yaşlı 1 baş Norduz ve 2 baş Kıl teke olmak üzere toplam 120 baş hayvan ile yapılıışır. Yaş gruplarına göre, Norduz ve Kıl keçi sayı ve oranları sırası ile; $9.6-13.8$ baş \% $9.9 \pm 1.37-\% 14.2 \pm 4.35$ iken, sürüde genel ortalama keçi sayısı ve canlı ağılık, sırası ile; 23.4 baş (\% $24.1 \pm 2.86)-46.72 \pm 4.80 \mathrm{~kg} /$ baş belirlenmiştir. Teke katımı, Eylül - Aralık arasında ortalama $88.0 \pm 6.78$ günde, $1 / 45$ erkek dişi oranında yapılmışır. Teke katımı dönemi bazı üreme parametreleri Norduz ve Kıl keçilerinde sırası ile; gebelik süresi $148.0 \pm 3.32-157.0 \pm 5.46$ gün, gebelik oranı $\% 78.0 \pm$ $4.64-\% 53.0 \pm 2.66$, geri dönme oranı \% $19.0 \pm 0.22-\% 27.0 \pm 1.67$, kısırlık oranı \% $13.0 \pm 0.18-\% 21.0 \pm 1.93$, teke katımı doğum arası mecburi kesim ve ölüm oranı $\% 4.26 \pm 0.08-\% 6.22 \pm 1.70$, oğlaklama sezonu $94.00 \pm 4.61-117.0 \pm 6.33$ (gün) olarak belirlenmiştir ( $\mathrm{P} \leq 0.05)$. Her yaş grubunda, Norduz keçilerinin teke katımı dönemi üreme özellikleri, istatistiki olarak, Kıl keçilerinin değerlerinden önemli düzeyde yüksek bulunmuştur $(p \leq 0.05)$. Norduz keçilerinin yüksek verim özelliğinin popülasyona aktarılması durumunda, ıslahta yeni ivmeler kazanılabilir.

Anahtar Kelimeler: norduz, kıl keçi, kısırlık, geri dönme, oğlaklama

\section{Some Reproductive Characteristics of Norduz and Kıl Goat on Meeting Season}

\begin{abstract}
In this study was conduct, Van Province Muradiye District extensive conditions of rural areas, grown 486 head flock of livestock 2 , 3, 4, 5 and 6> age groups 48 head Norduz and 69 head KIl goat and 4 elderly 1 head Norduz, 2 head KIl buck with total of 120 goat. According to age groups, Norduz and KIl goat numbers and proportions, respectively; $9.6-13.8$ head, $9.9 \pm 1.37 \%-14.2 \pm 4.35 \%$, mean 23.4 head $(24.1 \pm 2.86 \%)$ and live weight mean $46.72 \pm 4.80 \mathrm{~kg} /$ head determined. Meeting season between September to December mean $88.0 \pm 6.78$ day by $1 / 45$ male/female rate. Some breeding season parameters respectively were found in the Norduz and KIl goats respectively; gestation length $148.0 \pm 3.32-157.0 \pm 5.46$ (day), pregnancy rate $78.0 \pm 4.64 \%-53.0 \pm 2.66 \%$, non return rate $19.0 \pm 0.22 \%$ $-27.0 \pm 1.67 \%$, infertility rate $13.0 \pm 0.18 \%-21.0 \pm 1.93 \%$, between meeting season to kidding time to shaltered and dead goat rate 4.26

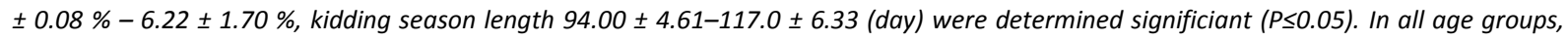
yield characteristics of Norduz goats were found to be higher than the values of KIl goats $(P \leq 0.05)$. It can be said that new breeds can be gained in breeding if the high yield characteristics of Norduz goats are transferred to the population.
\end{abstract}

Keywords: norduz, kıl goat, infertility, non return rate, kidding

\section{GiRiş}

Norduz ve Kıl keçi yetiştiriciliği, Doğu Anadolu Bölgesinde kırsal alandaki küçükbaş hayvan yetiştiricilerinin, en önemli hayvansal üretim kaynağıdır. Bölge kırsal alan nüfus artış hızı, hayvansal ürüne erişim hızından daima yüksek çıkmıştır. Kırsal alan küçükbaş hayvan yetiştiriciliği, bölgesel değişimler ve küçükbaş hayvan yetiştiriciliğinin, farklı nedenlerle gerilemesi ile (göçler, düşük verim, sosyo kültürel ve ekonomik değişimler, yetiştirme sistemleri, alternatif tüketim alışkanlıkları vs.) önce koyun popülasyonlarının azalmasına ve daha sonra da keçi popülasyonlarının ve keçi varlığının azalmasına neden olmuştur (Şengonca ve ark., 1983). Doğu Anadolu Bölgesi coğrafik, ekolojik ve sosyo-kültürel koşulları dikkate alındığında, bölge koşullarında en düşük maliyet ile hayvansal ürün, üretim kaynağı küçükbaş hayvan yetiştiriciliğidir (Kırk, 2005a). Bu koşullarda, mevcut küçükbaş hayvan yetiştiriciliği içindeki, keçi yetiştiriciliği verimlerinin ve buna bağlı olarak, gelirlerinin arttırılması, teke katımı dönemi, oğlak büyütme dönemi verim kayıplarının önlenme düzeyi kadar arttırılabilir (Gürsoy ve ark., 2003; Kırk, 2018). Birçok ulusal ve uluslar arası araştırmadan da izlendiği gibi, keçi yetiştiriciliği, kırsal alan bölge halkının, en önemli hayvansal üretim kaynağıdır. Norduz ve Kıl keçilerinin üreme etkinliğinin arttırılması için, teke katımı dönemi üreme özellikleri bilinmeyen erkek materyal damızık olarak kullanılmamalıdır. Böylece kendi koşullarında, üreme özellikleri bilinen tekeler ile, teke katımının yapılması durumunda, erkek materyalden kaynaklanabilecek kısırlık riski minimize edilebilir (Kaymakçı ve ark., 2005; Kırk, 2018; Ulutaş ve ark., 2010).

Doğu Anadolu Bölgesi kırsal alan ekstansif koşullarındaki keçi yetiştiriciliği, bitkisel ve diğer hayvansal üretim dallarının yapılamadığı, tüm alanlarda minimum maliyet ile optiumum gelir elde edilebilecek hayvansal üretim sistemidir (Demirören ve Taşkın., 1994; Sönmez., 1974). Norduz ve Kıl keçi yetiştiriciliğinde, üreme özelliklerinin, denetlenmesi, karışık sürü veya homojen sürülerde, elde edilecek hayvansal üretim gelirlerini doğrudan

Sorumlu Yazar: candemkkirk@gmail.com

Geliş Tarihi: 22 Şubat 2019

Kabul Tarihi: 27 Mayıs 2019 
etkileyecektir. Özellikle teke katımı dönemi, yetiştirme ve verim özelliklerinin iyileştirilmesi ve kontrolü, yapılacak hayvancılığın, bir sonraki generasyonun tüm verimlerini doğrudan etkileyecektir. Teke katımı döneminde uygulanan yetiştirme sistemi, aşım sezonu uzunluğu, aşım yöntemi, sürü kompozisyonu ve aşımda kullanılacak erkek ve dişi yaş ve oranı, tekelerin üreme ve damızlık özellikleri, teke katım canlı ağırlığı, gebelik süresi, döl verim oranı, kısırlık oranı, mecburi kesim ve ölüm oranı vb. gibi teke katımı dönemi parametreleri, yapılacak keçi yetiştiriciliğinin sürdürülebilir doğrudan etkileyecektir (Kırk, 2018; Kaymakçı ve ark., 2005). Bu nedenle bu araştırma, bölge koşullarında yapılan ekstansif Norduz ve Kıl keçi yetiştiriciliğinin, bölge küçükbaş hayvansal üretim ve tüketimindeki yerini koruyarak ve hatta bir üst seviyeye çıkararak göç, yetiştirme sisteminden vazgeçme veya alternatif üretim kaynaklarına yönelme vb. olumsuz kitlesel oluşumların, ekstansif keçi yetiştiricilik sistemini sonlandırması engellenebilir (Carol Delenay, 2018; Kırk ve Cebeci, 2017; Peacock ve Sherman., 2010).

Bu araştırma, Doğu Anadolu Bölgesi ekstansif koşullarında, koyun sürüleri ile birlikte karışık veya homojen sürüler halinde yetiştirilen, Norduz ve Kıl keçi varlığının, sürdürülebilir ve ekonomik hayvansal üretim düzeyine ulaşması için, teke katımı dönemi, üreme özelliklerini incelemek amacıyla yapılmıştır. Böylece, teke katımı döneminde, erkek materyal veya yetiştirme sistemi kaynaklı önlenebilecek üreme kusurları giderilerek; Norduz ve Kıl keçilerin, verim özellikleri genetik kapasite ve çevrenin müsaade ettiği en üst düzeye çıkarılabilecektir.

\section{MATERYAL ve YÖNTEM}

Van ili Muradiye ilçesi, kırsal bölge koşullarında bulunan, ekstansif sistemle yetiştirilen $2,3,4,5$ ve $6>$ yaş gruplarında 48 baş Norduz ve 69 baş Kıl keçi ile birlikte, 4 yaşlı 1 baş Norduz ve 2 baş Kıl teke olmak üzere toplam 120 baş keçi, araştırma materyali olarak kullanılmıştır.
Araştırmanın yapıldığı küçükbaş hayvan sürüsü ve içindeki keçi grubu, bölgede bulunan sürüler arasından tesadüfi olarak belirlenmiştir. Sürü içindeki Norduz ve Kıl keçiler, yaş gruplarına göre farklı renk boyalar ile işaretlenmiştir. Teke katımı döneminde; yaş gruplarına göre birey sayısı ve sürüdeki oranları canlı ağırlık (kg/baş), teke katımında erkek dişi oranı (1/45), teke katımı süresi (gün), gebelik süresi (gün), gebelik oranı (\%), geri dönme oranı (\%), kısırıı oranı (\%), teke katımı doğum arası dönemde mecburi kesim ve ölüm oranı (\%), oğlaklama sezonu (gün) gibi bazı üreme parametreleri belirlenmiştir. Elde edilen verilerin istatistiki analizlerinde ise SAS GLM, 2014 prosedürü kullanılmıştır.

\section{BULGULAR VE TARTIŞMA}

\section{Bulgular}

Norduz ve Kıl keçilerinin, teke katımı dönemindeki bazı üreme özellikleri incelenmiştir. Araştırma yapılan 486 baş'ık küçükbaş hayvan sürüsü içinde, mera'ya dayalı olarak yetiştirilen Norduz keçi sayısının toplam 48 baş olduğu ve farklı yaş gruplarına göre ortalama \% $9.9 \pm 1.37$ oranında, koyun sürüleri içinde karışık olarak yetiştirildiği belirlenmiştir (Çizelge 1). Gruplara göre Norduz keçi varlığı ve bu keçilerin sürüdeki oranları arasında istatistiki olarak önemli düzeyde farklılıklar olduğu belirlenmiştir ( $P \leq 0.05)$. Bölge küçükbaş hayvan yetiştiriciliği incelendiğinde, bu farklılıkların daha uzun bir laktasyon süresi ve yüksek verim alabilmek için özellikle verime dayalı ıslah ve seleksiyon çabalarından kaynaklandığı söylenebilir.

Aynı çalışmada, 2 - 6> yaş aralığındaki Kıl keçilerinin, 486 baş'lık küçükbaş hayvan sürüsü içinde, 2, 3, 4, 5 ve 6> yaş gruplarında 9 ile 14 baş olarak yetiştirildiği belirlenmiştir. Araştırma yapılan 486 baş'lık, küçükbaş hayvan sürüsü içinde, mera'ya dayalı olarak yetiştirilen, Kıl keçi sayısının toplam 69 baş olduğu ve farklı yaş gruplarına göre ortalama \% $14.2 \pm 4.35$ oranında, koyun sürüleri içinde karışık olarak yetiştirildiği belirlenmiştir (Çizelge 1 ). Koyun sürüsü içinde

Çizelge 1. Norduz ve kıl keçilerinin sürü kompozisyonundaki dağılımları

\begin{tabular}{llll}
\hline \multirow{2}{*}{ Yaş Grupları } & Irklar & \multicolumn{2}{c}{ Özellikler } \\
\cline { 3 - 4 } 2 & & Sürüdeki Sayısı(n/baş) & Sürüdeki Oranı(\%) \\
\hline \multirow{2}{*}{3} & Norduz & 12.0 & $2.47 \pm 1.09$ \\
& Kıl & 14.0 & $2.89 \pm 2.38$ \\
& Norduz & 9.0 & $1.85 \pm 1.13$ \\
4 & Kıl & 17.0 & $3.50 \pm 3.22$ \\
& Norduz & 11.0 & $2.26 \pm 1.26$ \\
5 & Kıl & 13.0 & $2.67 \pm 4.37$ \\
& Norduz & 6.0 & $1.23 \pm 2.19$ \\
\multirow{2}{*}{ Toplam } & Kıl & 16.0 & $3.29 \pm 5.57$ \\
& Norduz & 10.0 & $2.06 \pm 1.17$ \\
\hline
\end{tabular}


karışık olarak yetiştirilen Kıl keçilerin, 2, 3, 4, 5 ve 6> yaş gruplarına göre keçi sayıları bakımından, gruplar arasındaki farklılığın, istatistiki olarak önemsiz olduğu $(P \leq 0.05)$, ancak bu durumun, koyunlardan elde edilen laktasyon süresinden daha uzun laktasyon süresinde, koyunlardan daha yüksek düzeyde laktasyon verimine ulaşmak için uygulanan, geleneksel küçükbaş hayvan yetiştirme davranışı olduğu belirlenmiştir.
Eylül - Aralık ayları arasındaki periyot, bölge koşullarının teke katımı dönemi olup, Norduz ve Kıl keçilerinin bu periyottaki, 1/45 erkek dişi oranı ile sırası ile Norduz keçileri ortalama $49.0 \pm 3.23 \mathrm{~kg} /$ baş canlı ağırlıkta iken, ortalama $79.0 \pm 4.99$ gün süre ile teke katımı uygulandığı, Kıl keçilerinde ise ortalama $44.44 \pm 6.36 \mathrm{~kg} / \mathrm{baş} \mathrm{canlı} \mathrm{ağırlıkta}$ $97.0 \pm 8.56$ günlük periyotta teke katımı uygulandığı belirlenmiştir (Çizelge 2 ).

Çizelge 2. Norduz ve kıl keçilerinin teke katımı dönemi özellikleri

\begin{tabular}{|c|c|c|c|c|c|}
\hline \multirow[b]{2}{*}{ Yaş Grupları } & \multirow[b]{2}{*}{ Irklar } & \multicolumn{4}{|c|}{ Özellikler } \\
\hline & & $\begin{array}{l}\text { Sürüdeki Keçi } \\
\text { Sayısı (n/baş) }\end{array}$ & $\begin{array}{l}\text { Teke Katımı Süresi } \\
\text { (gün) }\end{array}$ & $\begin{array}{l}\text { Teke Katım Oranı } \\
\text { (\%) }\end{array}$ & $\begin{array}{l}\text { Canlı Ağırlık Ort. } \\
\text { (kg/baş) }\end{array}$ \\
\hline \multirow{2}{*}{2} & Norduz & 12.0 & $89.6 \pm 8.34$ & $1 / 30$ & $41.3 \pm 2.10$ \\
\hline & Kıl & 14.0 & $98.9 \pm 11.26$ & $1 / 30$ & $36.8 \pm 6.07$ \\
\hline \multirow{2}{*}{3} & Norduz & 9.0 & $79.5 \pm 7.13$ & $1 / 30$ & $46.7 \pm 3.01$ \\
\hline & Kıl & 17.0 & $98.7 \pm 9.43$ & $1 / 30$ & $40.6 \pm 5.35$ \\
\hline \multirow{2}{*}{4} & Norduz & 11.0 & $76.2 \pm 5.61$ & $1 / 50$ & $51.5 \pm 3.89$ \\
\hline & Kıl & 13.0 & $99.2 \pm 7.16$ & $1 / 50$ & $44.7 \pm 4.98$ \\
\hline \multirow{2}{*}{5} & Norduz & 6.0 & $75.3 \pm 2.11$ & $1 / 55$ & $54.8 \pm 2.96$ \\
\hline & Kıl & 16.0 & $96.1 \pm 8.13$ & $1 / 55$ & $48.6 \pm 6.47$ \\
\hline \multirow{2}{*}{$6>$} & Norduz & 10.0 & $74.4 \pm 1.77$ & $1 / 60$ & $50.6 \pm 4.21$ \\
\hline & Kıl & 9.0 & $92.1 \pm 6.81$ & $1 / 60$ & $51.5 \pm 8.94$ \\
\hline \multirow{2}{*}{ Toplam } & Norduz & 9.6 & $79.0 \pm 4.99$ & $1 / 45$ & $49.0 \pm 3.23$ \\
\hline & Kıl & 13.8 & $97.0 \pm 8.56$ & $1 / 45$ & $44.4 \pm 6.36$ \\
\hline
\end{tabular}

Mera koşullarında, doğal aşım ile serbest olarak katılan, Norduz keçilerinin teke katım canlı ağırlıklarının, Kıl keçilerin teke katımı canlı ağırığından istatistiki olarak önemli düzeyde yüksek olduğu belirlenmiştir ( $p \leq 0.01)$. Bu durum, teke katımı canlı ağırlığı bakımından, Norduz keçilerinin genetik olarak, Kıl keçilerinden üstün olduklarını ortaya koymuştur. Araştırmada, Norduz ve Kıl keçilerinin, teke

katımı dönemi bazı üreme özellikleri Çizelge 3-4'te
görülmektedir.

Norduz keçilerinin bazı üreme özellikleri sırası ile; gebelik süresi $145.3 \pm 1.63-152.0 \pm 4.16$ gün arasında (ortalama $148.0 \pm 3.32$ gün), gebelik oranı $\% 67.5 \pm 0.28-85.3 \pm 0.10$ arasında (ortalama \% $78.0 \pm 4.64$ ), geri dönme oranı \% 10.5 \pm 0.17 - $27.8 \pm 0.41$ arasında (ortalama \% $19.0 \pm 0.22$ ), kısırlık oranı \% $10.8 \pm 0.11-15.7 \pm 0.12$ arasında (ortalama

Çizelge 3. Norduz keçilerinin bazı üreme özellikleri

\begin{tabular}{|c|c|c|c|c|c|c|}
\hline \multirow{2}{*}{ Özellikler } & \multicolumn{5}{|c|}{ Yaş Grupları } & \multirow[b]{2}{*}{ Ortalama } \\
\hline & 2 & 3 & 4 & 5 & 6> & \\
\hline Keçi Sayısı (\%) & 12.0 & 9.0 & 11.0 & 6.0 & 10.0 & 9.9 \\
\hline Gebelik Süresi (gün) & $152.0 \pm 4.16$ & $149.4 \pm 5.29$ & $147.1 \pm 3.41$ & $146.2 \pm 2.13$ & $145.3 \pm 1.63$ & $148.0 \pm 3.32$ \\
\hline Gebelik Oranı (\%) & $67.5 \pm 0.28$ & $73.3 \pm 1.14$ & $79.3 \pm 0.53$ & $84.6 \pm 0.27$ & $85.3 \pm 0.10$ & $78.0 \pm 4.64$ \\
\hline Geri Dönme Oranı (\%) & $27.8 \pm 0.41$ & $24.5 \pm 0.37$ & $20.4 \pm 0.06$ & $11.8 \pm 0.03$ & $10.5 \pm 0.17$ & $19.0 \pm 0.22$ \\
\hline Kısırlık Oranı (\%) & $15.7 \pm 0.12$ & $14.6 \pm 0.23$ & $12.4 \pm 0.36$ & $11.5 \pm 0.08$ & $10.8 \pm 0.11$ & $13.0 \pm 0.18$ \\
\hline Teke Katımı Doğum & & & & & & \\
\hline $\begin{array}{l}\text { Arası Dönemde Mecburi } \\
\text { Kesim ve Ölüm Oranı (\%) }\end{array}$ & $3.4 \pm 0.03$ & $3.5 \pm 0.01$ & $4.4 \pm 0.26$ & $4.8 \pm 0.06$ & $5.2 \pm 0.04$ & $4.26 \pm 0.08$ \\
\hline Oğlaklama Sezonu (gün) & $101.1 \pm 7.86$ & $98.4 \pm 5.65$ & $97.5 \pm 2.33$ & $87.9 \pm 4.08$ & $85.1 \pm 3.14$ & $94.00 \pm 4.61$ \\
\hline
\end{tabular}

Çizelge 4. Kıl keçilerinin bazı üreme özellikleri

\begin{tabular}{|c|c|c|c|c|c|c|}
\hline \multirow{2}{*}{ Özellikler } & \multicolumn{5}{|c|}{ Yaş Grupları } & \multirow[b]{2}{*}{ Ortalama } \\
\hline & 2 & 3 & 4 & 5 & 6> & \\
\hline Keçi Sayısı (\%) & 14.0 & 17.0 & 13.0 & 16.0 & 9.0 & 13.8 \\
\hline Gebelik Süresi (gün) & $159.2 \pm 7.09$ & $158.6 \pm 5.11$ & $157.9 \pm 6.09$ & $155.2 \pm 3.54$ & $154.1 \pm 5.48$ & $157.0 \pm 5.46$ \\
\hline Gebelik Oranı (\%) & $49.7 \pm 1.71$ & $51.1 \pm 3.48$ & $54.5 \pm 2.19$ & $55.4 \pm 3.73$ & $54.3 \pm 2.18$ & $53.0 \pm 2.66$ \\
\hline Geri Dönme Oranı (\%) & $32.3 \pm 1.89$ & $31.4 \pm 1.13$ & $25.2 \pm 2.05$ & $26.1 \pm 1.17$ & $20.0 \pm 2.11$ & $27.0 \pm 1.67$ \\
\hline Kısırlık Oranı (\%) & $25.0 \pm 2.39$ & $23.2 \pm 1.23$ & $18.5 \pm 1.42$ & $19.3 \pm 2.87$ & $19.0 \pm 1.72$ & $21.0 \pm 1.93$ \\
\hline Teke Katımı Doğum & & & & & & \\
\hline $\begin{array}{l}\text { Arası Dönemde Mecburi } \\
\text { Kesim ve Ölüm Oranı (\%) }\end{array}$ & $7.5 \pm 1.40$ & $6.3 \pm 2.57$ & $6.5 \pm 1.07$ & $5.6 \pm 1.53$ & $5.2 \pm 1.89$ & $6.22 \pm 1.70$ \\
\hline Oğlaklama Sezonu (gün) & $119.5 \pm 9.83$ & $118.5 \pm 6.17$ & $116.7 \pm 5.98$ & $114.8 \pm 3.77$ & $115.5 \pm 5.91$ & $117.0 \pm 6.33$ \\
\hline
\end{tabular}


$\% 13.0 \pm 0.18)$, teke katımı doğum arası dönemde mecburi kesim ve ölüm oranı $3.4 \pm 0.03-5.2 \pm 0.04$ arasında (ortalama \% $4.26 \pm 0.08$ ) ve oğlaklama sezonu $85.1 \pm 3.14$ $101.1 \pm 7.86$ gün arasında (ortalama $94.00 \pm 4.61$ gün) olarak belirlenmiştir (Çizelge 3). Bu araştırmanın bazı parametreleri incelendiğinde, Norduz keçilerinin, teke katımı dönemi bazı üreme özelliklerinin yaş gruplarına göre dağılımları incelendiğinde, gebelik süresi, gebelik oranı, geri dönme oranı, kısırlık oranı ve oğlaklama sezonu gibi parametreler bakımından gruplar arasında istatistiki olarak önemli farklılıklar olduğu, teke katımı doğum arası dönemde mecburi kesim ve ölüm oranı bakımından ise yaş grupları arasında istatistiki olarak önemli farklılıklar olmadığı gözlemlenmiştir(p<0.05). Bu durum elde edilen parametrelerin yüksek varyasyonundan kaynaklandığı, Norduz keçilerinin genetik ve çevresel faktörlerin etkisi ile, bölge koşullarında yüksek süt verimli keçi popülasyonlarının geliştirilmesi ve yaygınlaştırılmasında, Damascus keçileri gibi ıslah edici ırk, baba materyal olarak kullanılabilecekleri söylenebilir.

Kıl keçilerinin teke katımı dönemi bazı üreme özellikleri incelendiğinde sırası ile; gebelik süresi $154.1 \pm 5.48-159.2 \pm$ 7.09 arasında (ortalama $157.0 \pm 5.46$ gün), gebelik oranı \% $49.7 \pm 1.71-55.4 \pm 3.73$ arasında (ortalama \% $53.0 \pm 2.66$ ), geri dönme oranının \% $20.0 \pm 2.11-32.3 \pm 1.89$ arasında (ortalama \% $27.0 \pm 1.67$ ), kısırlık oranı \% $18.5 \pm 1.42-25.0 \pm$ 2.39 arasında (ortalama \% $21.0 \pm 1.93$ ), teke katımı doğum arası dönemde mecburi kesim ve ölüm oranı $5.2 \pm 1.89-7.5$ \pm 1.40 arasında (ortalama \% $6.22 \pm 1.70$ ) ve oğlaklama sezonu $114.8 \pm 3.77$ - $119.5 \pm 9.83$ (gün) arasında (ortalama $117.0 \pm 6.33$ gün) olarak tespit edilmiştir (Çizelge 4). Bu araştırma ile, teke katımı dönemi Kıl keçilerin bazı döl verim parametreleri incelendiğinde, Kıl keçilerin teke katımı dönemi bazı üreme özellikleri; gebelik süresi, gebelik oranı, geri dönme oranı, kısırlık oranı ve oğlaklama sezonu gibi parametreler bakımından, gruplar arasında istatistiki olarak önemli farklılıklar olduğu, teke katımı doğum arası dönemde mecburi kesim ve ölüm oranı bakımından ise yaş grupları arasında istatistiki olarak önemli farklılıklar olmadığı gözlemlenmiştir ( $p \leq 0.05)$. Bu durum elde edilen parametrelerin yüksek varyasyonundan kaynaklandığı, bu varyasyonun ise popülasyonun ıslahı açısından aranılan önemli avantaj olduğu, Kıl keçilerinin genetik ve çevresel faktörlerin etkisi ile, bölge koşullarında yüksek adaptasyon ile doğal seleksiyon sonucu bu günkü verim özelliklerine ulaştığını ortaya koymuştur. Kıl keçi popülasyonlarının, saf yetiştirme ve seleksiyon ile ıslah programlarına dahil edilmeleri durumunda, gelecek generasyon keçi popülasyonlarının ana kadrosunu oluşturarak sürülerin sayıca artmasının en önemli kaynağını Kıl keçilerin oluşturabileceği söylenebilir. Kıl keçi popülasyonlarındaki bu potansiyel Anadolunun her bölgesi için vazgeçilmeyen ve korunması gereken bir gen kaynağı olarak orjinalliği bozulmadan, doğru ve etkin ıslah programları uygulanarak kırsal alan köylülerinin birim keçi sayısı ve keçi başına düşen verimi arttırılabilir.

\section{Tartışma}

Doğu Anadolu Bölgesi koşullarında, Norduz ve Kıl keçi yetiştiriciliğinde, döl verim özellikleri düzeyinin, koyun sürüleri içinde karışık yetiştirilen, değişen yaşlı Norduz ve Kıl keçi gruplarının tüm verim özelliklerini doğrudan önemli düzeyde etkilediği belirlenmiştir ( $\mathrm{P} \leq 0.05)$. Buna göre; Doğu Anadolu Bölgesi yetiştiricilerinin, keçi yetiştirmelerinin, yıl boyu keçi ürünleri üretim ve tüketiminin geleneksel yetiştirme sisteminden kaynaklandığı belirlenmiştir. Bu araştırmada, 486 baş’lık küçükbaş hayvan sürüsü içindeki Norduz ve Kıl keçilerinin, her yaş grubundan 9.6 - 13.8 baş olmak üzere, toplam 23.4 baş ve $\% 9.9 \pm 1.37$ oranında Norduz keçisi, \% $14.2 \pm 4.35$ oranında ise Kıl keçi olmak üzere genel ortalama \% $24.1 \pm 2.86$ oranında keçi yetiştirildiği belirlenmiştir. Bu durum bölge yetiştiricilerinin sürdürülebilir ekonomik küçükbaş hayvansal üretim amaçlarının olduğunu açıkça ortaya koymaktadır. Bununla birlikte Norduz ve Kıl keçilerinin teke katımı dönemi (Eylül Aralık); arasındaki periyotta sırası ile genel ortalama, 2 - 6> yaşlı Norduz ve Kıl keçi gruplarının, $46.72 \pm 4.80 \mathrm{~kg} /$ baş canlı ağırlıkta iken, $88.0 \pm 6.78$ teke katımı süresinde, $1 / 45$ erkek dişi oranında teke katıldığı belirlenmiş olup, bu değerlerin ulusal ve uluslararası literatür ile uyum gösterdiği söylenebilir (Carol Delaney, 2018; Gürsoy ve ark., 2003; Kırk, 2006). Teke katımı dönemi bazı üreme parametreleri incelendiğinde, gebelik süresi, $148.0 \pm 3.32$ gün, gebelik oranı \% $78.0 \pm 4.64$, geri dönme oranı $\% 19.0 \pm 0.22$, kısırlık oranı \% $13.0 \pm 0.18$, teke katımı doğum arası dönemde mecburi kesim ve ölüm oranı $\% 4.26 \pm 0.08$, oğlaklama sezonu ise $94.00 \pm 4.61$ (gün) olarak belirlenmiştir $(P \leq 0.05)$. (Dyrmundson, 2006; Peacock ve Sherman, 2010). Aynı koşullarda Kıl keçilerinin teke katımı dönemi bazı üreme özellikleri genel ortalaması ise sırası ile; gebelik süresi, $157.0 \pm 5.46$ gün, gebelik oranı $\% 53.0 \pm 2.66$, geri dönme oranı \% $27.0 \pm 1.67$, kısırlık oranı \% $21.0 \pm 1.93$, teke katımı doğum arası dönemde mecburi kesim ve ölüm oranı \% 6.22 \pm 1.70 ve oğlaklama sezonu $117.0 \pm 6.33$ (gün) olarak tespit edilmiştir ( $\mathrm{P} \leq 0.05)$ (Kırk, 2005b). Bu araştırmadan elde edilen veriler referans olarak değerlendirildiğinde, Doğu Anadolu Bölgesi kırsal alan koşullarında, koyun sürüleri ile karışık veya homojen sürüler halinde keçi yetiştiriciliği, bölge hayvansal üretiminin, en önemli sürdürülebilir ekonomik üretim koşuludur (Şengonca ve ark.,1983). Çünkü bu sistem ile Anadolu'da kendi koşullarında yıl içinde mevsimlere yayılan en az masraf ile hayvansal üretim şeklidir. Eğer bu sürülere saf yetiştirme ve seleksiyon ile ıslah yapılabilirse, gelecek generasyonlarda hem verim özelliği yüksek keçi varlığı hem de birim keçi başına maksimum verim elde edilebilecektir (Belanchea ve ark., 2019; Kırk, 2018).

$\mathrm{Bu}$ araştırmada elde edilen sonuçlara göre, Norduz ve Kıl keçi yetiştiriciliği, küçükbaş hayvan yetiştiriciliğinden elde edilen hayvansal ürünlerin yıl boyunca yayılması için, en ekonomik hayvansal üretim kaynağı olduğu söylenebilir. 


\section{KAYNAKLAR}

Belanchea A, Martín-Garcíaa Al, Fernández-Álvarezb J, Pleguezuelosb J, Mantecónc AR, David RRY (2019) Optimizing management of dairy goat farms through individual animal data interpretation: A case study of smart farming in Spain. Agricultural System, July 2019 173, pp 27-38.

Carol Delaney MS (2018) Thinking outside the box: Innovative solutions for dairy goat management. Small Ruminant Research 163: 39-44.

Demirören E, Taşkın T (1994) Bornova, Saanen ve SaanenXKilis Genotipine Ait Keçilerin Süt Verim Özellikleri Üzerine Bir Araştırma. Hayvansal Üretim Dergisi, 35:55-62.

Dyrmundson OR (2006) Sustainability of sheep and goat production in North European countries From the Arctic to the Alp. Small Ruminant Research 62 (3): 151-157.

Ulutaş Z, Kuran M, Şirin E, Aksoy Y. 2010. Tokat şartlarında yetiştirilen Saanen ırkı keçilerin döl, süt verimi ve oğlakların gelişme özelliklerinin belirlenmesi, Ulusal Keçicilik Kongresi Bildiriler Kitabı, Çanakkale, 24-26 Haziran, 215- 218.

Gürsoy O, Acuz S, Kırk K, Şentut T, Bilgiç i (2003) Preliminary Evaluation of the Project Use of Kermes Oak (Quercus coccifera L.) Acorn for Increasing Reproductive Performance of Goats on the Highlands of Anti-Taurus Mountains. Extendent Abstracts of Workshop on 'Ecosystems-based assessment of soil degradation to facilitate land users' and land owners' prompt actions 'ECOLAND Adana, Turkey, 2-7 June 2003. p: 130-133.

Kaymakçı M, Tuncel E, Güney O (2005) Türkiye'de Süt Keçisi Islahı Çalışmaları. Süt Keçiciliği Ulusal Kongresi Bildirileri, 26-27 Mayıs 2005. Ege Üniversitesi Ziraat Fakültesi Zootekni Bölümü, sayfa 4-10. İzmir.

Kırk K (2005a) Doğu Anadolu Bölgesi Kırsal Kalkınma Sürecinde Yeni Süt Keçisi Yetiştirme Modellerinin Geliştirilmesi ve Yaygınlaştırılmasının Aile ve Bölge
Ekonomisine Katkıları. I. Doğu Anadolu Sempozyumu (Bölgesel Kalkınmada Yeni Ufuklar), 23-25 Mayıs 2005 sayfa, 186-195, Elazığ.

Kırk K (2005b) Doğu Anadolu Bölgesi'nde Süt Keçiciliğinin Geliştirilmesi. Süt Keçiliği Ulusal Kongresi, 26-27 Mayıs 2005. Ege Üniv. Ziraat Fakültesi Zootekni Bölümü, sayfa $219-227$, İzmir.

Kırk K (2006) Doğu Anadolu Bölgesi Kırsal Kalkınma Sürecinde Sürdürülebilir Küçükbaş Hayvan Yetiştiriciliğinin Önemi ve Mevcut Koşullarda Üretim ve Tüketim Politikalarının Geliştirilmesi ve Yaygınlaştırılması. Ulusal Tarım Kurultayı 15-17 Kasım 2006. Çukurova Üniversitesi Ziraat Fakültesi, sayfa, 157-163, Adana.

Kırk K, Cebeci T (2017) Göçer Keçi Yetiştiriciliğinin Modern Süt Keçisi Yetiştiriciliğine Dönüşümünün Bölge Hayvansal Üretimine Katkıları. II. Ulusal Hayvancılık Ekonomisi Kongresi, 27-30 Nisan 2017, sayfa 211216, Antalya.

Kırk K (2018) Kırsal Alan Keçi Popülasyonlarının Verim Özellikleri. IKSAD-iktisadi Kalkınma ve Sosyal Araştırmalar Derneği. Ahtamara I.Uluslararası Multidisipliner Çalışmalar Kongresi 25-26 Ağustos, p. 313, Van.

Peacock C, Sherman DM (2010) Sustainable goat production some global perspectives. Small Ruminant Research 89 (2-3): 70-80.

SAS (2014) Statistical Analysis System. SAS Institute Inc., Cary, N.C.USA

Sönmez R (1974) Melezleme Yolu İle Yerli Kıl Keçilerinin, Süt Keçisine Çevrilme Olanakları. Ege Üniversitesi Ziraat Fakültesi Yayınları No: 226, İzmir.

Şengonca, M., M. Kaymakçı, R. Sönmez, 1983. Ege Bölgesi'nde Yetiştirilen Süt Keçilerinin Melezleme Yoluyla Islah Olanakları (1. Kademe Projesi), Doğa Bilim Derg.: Veterinerlik ve Hayvancılık Cilt 7, 257263. 
